\title{
A DYNAMIC COMPENSATION METHOD FOR NATURAL AMBIENT DOSE RATE BASED ON 6 YEARS DATA FROM THE DUTCH RADIOACTIVITY MONITORING NETWORK
}

\author{
R. C. G. M. Smetsers and R. O. Blaauboer \\ National Institute of Public Health and the Environment (RIVM) \\ Laboratory of Radiation Research \\ PO Box 1, 3720 BA Bilthoven, The Netherlands
}

Received April 23 1996, Amended July 4 1996, Accepted July 91996

\begin{abstract}
The significant variations in time exhibited by background radiation hinders a sensitive recognition of human-induced factors. A comprehensive study in the Netherlands has examined the influence of the various natural processes on the natural background using six years data from the Dutch nuclear emergency network. Results presented concentrate on temporal variations in ambient dose-equivalent rate, $\dot{H}^{*}(10)$, and have led to simple expressions to model the ambient dose rate using a limited set of readily available parameters, i.e. air pressure, deposition rate and equilibrium equivalent decay product concentration of ${ }^{222} \mathrm{Rn}$, EEDC. Best values and uncertainty ranges of the applied parameters are reported. Remaining variations, e.g. due to variations in the cosmic radiation intensity and the radon soil profile, are shown to be small in the Netherlands, with one exception when the cosmogenic dose rate at sea level was decreased for a period of months due to a global deflection of the earth's magnetic field in the summer of 1991. The resulting compensation method for the natural ambient dose rate enables sensitive detection of anomalies, supporting the surveillance of nuclear installations and the management of nuclear emergency networks.
\end{abstract}

\section{INTRODUCTION}

Background ionising radiation levels in the outdoor environment have been subject to many studies and the knowledge built up over the years has led to an adequate understanding of the general nature of natural radiation sources and processes ${ }^{(1)}$. However, some details required for a precise quantification of the natural background and its variations in space and time are still lacking. This level of detail is necessary, for instance, to identify the influence of the human factor on radiation levels observed in practice. Solving the problem of discriminating between natural and human-induced contributions to the radiation environment has for several reasons become more difficult lately. First, there is a tendency to decrease the legitimate degree of 'manmade' radiation ${ }^{(2.3)}$. Nowadays dose rate limits, as established in government permits, are often lower than the range of temporal variations due to natural causes. Secondly, much attention is now focused on 'humanenhanced' sources of natural radioactivity, where nuclidespecific measurements cannot be applied to discriminate between the various sources of radioactivity present.

The last extensive outdoor radiation surveys in the Netherlands, performed some 10 years ago, yielded valuable (geographical) information, but they produced either time-averaged ${ }^{(4)}$ or momentary data ${ }^{(5)}$, neither of them suited to studying the dynamics of natural processes. Much information on the dynamics of the natural radiation background is available in the literature, but most studies are focused on one particular process, using a limited set of data obtained at one location ${ }^{(6-9)}$. Moreover, many results from abroad were obtained under different environmental circumstances and may not be valid for the situation in the Netherlands

The development of the Dutch National Radioactivity Monitoring network (NRM) for nuclear emergency response ${ }^{(10)}$ provided an opportunity to present a complete and coherent evaluation of all relevant sources and processes contributing to the outdoor radiation environment in the Netherlands. The objectives of an ongoing study analysing the variations in the natural background and examining the processes and mechanisms responsible for it have been described recently, along with some preliminary results ${ }^{(11)}$. The present paper concentrates on one part of this study, i.e. the analysis of temporal variations in ambient dose-equivalent rate, $\dot{H}^{*}(10)$. The aim was to provide (simple) expressions to model the dynamics in natural ambient dose rate (including best estimates and uncertainty ranges for the applied parameters), to present a practical compensation method for the natural background enabling a quick and sensitive identification of anomalies and to demonstrate the applicability of this technique.

\section{INSTRUMENTATION}

Radiological data used for this study (10 min recordings of external irradiation levels at 58 locations and airborne radioactivity at 14 locations) were collected by the NRM in the period 1990-1995. NRM locations are identified by their names, followed by a 3-digit number in brackets, like 'Vlaardingen (433)'. Technical specifications of the network, including location numbers and positions, and its performance as an emergency network can be found in a recent 
paper ${ }^{(10)}$. NRM data have been shown to meet the requirements for studying the dynamics in the natural background in great detail ${ }^{(1-13)}$; the information presented here is therefore restricted to the essentials.

For the monitoring of external irradiation levels the NRM is equipped with proportional counters (Bitt Technology Inc., RS02 tube with an accessory RM10E readout unit $\left.{ }^{(14)}\right)$. Recordings are converted to the dosimetric quantity ambient dose-equivalent rate at $10 \mathrm{~mm}$ depth, $\dot{H}^{*}(10)^{(15)}$. In this paper, this quantity is abbreviated to ambient dose rate, and symbolised by $\dot{H}^{*}$. The NRM dose rate meters hold some systematic errors (for instance, they overestimate the cosmogenic dose rate), but these errors are correctable and do not affect the dynamic response of the equipment ${ }^{(13)}$. The reproducibility and mutual interchangeability of the applied radiation counters were shown to be very satisfactory; the accuracy of the data is, apart from counting statistics, estimated at $1 \%\left(1 \sigma_{\text {rel }}\right)$ for typical background levels ${ }^{(11,13)}$. The counter tubes are mounted $1 \mathrm{~m}$ above the rooftop of the NRM measuring cabins, about $3.5 \mathrm{~m}$ above ground level. Although most NRM locations are found in rural areas, ambient dose rate recordings are influenced by the presence of pavements or small structures in the vicinity of the measuring sites ${ }^{(13,16)}$.

Recordings of airborne radioactivity are conducted using a moving tape air sampler (FAG Kugelfischer Georg Schäfer KGaA FRG, type: FHT 59S $\left.{ }^{(17)}\right)$. It was shown $^{(12)}$ that recordings of natural gross $\alpha$ activity concentrations in air can be converted to the actual equilibrium equivalent decay product concentration of ${ }^{222} \mathrm{Rn}$, $\operatorname{EEDC}^{(18)}$. The total uncertainty $\left(1 \sigma_{\mathrm{rel}}\right)$ in the determination of the EEDC is estimated at $12 \%$. Any contribution of ${ }^{220} \mathrm{Rn}$ progeny to the initial recordings can be neglected for various reasons, one of them being the air sampling height of almost $5 \mathrm{~m}^{(12)}$.

Meteorological data are supplied by the Royal Netherlands Meteorological Institute (KNMI). Additional information on wet deposition was obtained from a calibrated 'tipping bucket' rainfall monitor (Rotronic OMC 210, time period $10 \mathrm{~min}$ ) located at the NRM station Bilthoven (627).

\section{METHODOLOGY}

Cosmogenic (COS) and terrestrial (TER) radiation, as well as $\gamma$ radiation from airborne (AIR) and deposited (DEP) decay products of ${ }^{222} \mathrm{Rn}$, control the natural background of 'long-range' ionising radiation in the outdoor environment. Their time-varying contributions to the ambient dose rate, present at a certain spot, $\dot{\mathrm{H}}_{\mathrm{NAT}}^{*}(\mathrm{t})$, may in general be written as:

$$
\begin{aligned}
\dot{\mathrm{H}}_{\mathrm{NAT}}^{*}(\mathrm{t})= & \dot{\mathrm{H}}_{\mathrm{COS}}^{*}+\Delta \dot{\mathrm{H}}_{\mathrm{COS}}^{*}(\mathrm{t})+\dot{\mathrm{H}}_{\mathrm{TER}}^{*} \\
& +\Delta \dot{\mathrm{H}}_{\mathrm{TER}}^{*}(\mathrm{t})+\dot{\mathrm{H}}_{\mathrm{AIR}}^{*}(\mathrm{t})+\dot{\mathrm{H}}_{\mathrm{DEP}}^{*}(\mathrm{t})
\end{aligned}
$$

The contribution from cosmogenic radiation is represented by a constant level, $\dot{\mathrm{H}}_{\mathrm{C}}^{*}$, being the long-term time-averaged value, with a comparatively small timevarying component, $\Delta \dot{H}_{C}^{*} \operatorname{los}(t)$, superimposed. The latter function may be either positive or negative. The same holds for terrestrial radiation, where $\Delta \dot{H}_{\mathrm{TER}}^{*}(\mathrm{t})$ denotes the time-varying component, but the corresponding constant, $\dot{H}_{\text {TER }}^{*}$ is soil- and thus location-dependent and may also be affected by building materials. The contributions from airborne and deposited radioactivity, denoted as $\dot{\mathrm{H}}^{*}{ }_{\mathrm{AIR}(\mathrm{t})}$ and $\dot{\mathrm{H}}^{*}{ }_{\mathrm{DEP}(\mathrm{t})}$, respectively, are both equal to or larger than zero. In this paper simple expressions will be given to approximate these functions, using environmental parameters whose development with time is readily available. This is done essentially by fitting the parameters of attempted functions for the various elements of Equation 1, derived from general theory, with measured time-series of radiological and meteorological data. Where this was not feasible, at least the margins of the fluctuation band were determined.

NRM dose rate meters are unable to discriminate between contributions from various sources, so other techniques had to be used to evaluate the influence of each process separately. The analysis was therefore carried out in successive steps. First, data were selected in such a way that the influence of some processes could be ignored, leaving only a limited number of parameters for explaining most of the observed variations. In the following step, 'explained' variations were subtracted from the initial data and the residuals were used to examine the influence of other sources, and so on. One selection criterion applied to all analysis steps was to omit all data which had possibly been disturbed by human interference other than the systematic influence of building materials. Standard methods for statistical analysis (e.g. linear regression analysis), were applied to examine the observed variations and to determine best values and uncertainty intervals for the process parameters involved.

\section{RESULTS OF THE DATA ANALYSIS}

\section{Stage 1: Dry periods}

In the first stage of the analysis, data probably influenced by washout and rainout of airborne radioactivity were rejected $\left(\dot{\mathrm{H}}_{\mathrm{DEP}}^{*}(\mathrm{t})\right.$ equals zero). This leaves us with the following (time-varying) radiation sources:

(1) The cosmogenic dose rate at ground level is affected by the total amount of air mass present in the stratospheric and trophospheric layers. The atmospheric pressure observed at the measuring spot is a good indicator of the total air column present above the spot. At sea level the variation in air pressure is limited to a comparatively small range of approximately $80 \mathrm{hPa}$ where the average value is close to the standard air pressure, $\mathrm{p}_{\mathrm{o}}=1013 \mathrm{hPa}^{(19)}$; the dependence of the cosmogenic dose rate on the air 
pressure can therefore be approximated by a linear relationship.

(2) Next, we have the terrestrial dose rate. When the concentrations and distributions of the various radionuclides contained in the surrounding soil are known, the terrestrial dose rate can be calculated $^{(13,16)}$. Alternatively, 'free-field' terrestrial dose rates can be estimated on the basis of general soil characteristics ${ }^{(13)}$. However, a precise value of this background level has to be determined experimentally, due to the unknown influence of the built-up environment. For the moment, we will neglect the term $\Delta \dot{\mathrm{H}}_{\text {TER }}^{*}(\mathrm{t})$ in Equation 2, which is relatively small in the Netherlands

(3) In addition, radiation emerging from $\gamma$-emitting radionuclides in the air, dominated by the presence of the ${ }^{222} \mathrm{Rn}$ decay products ${ }^{214} \mathrm{Bi}$ and ${ }^{214} \mathrm{~Pb}$, contributes a varying amount to the ambient dose rate. When we assume the vertical profile of these radionuclides in the air to be invariable, their contribution to the ambient dose rate is linearly proportional to the activity concentration of each nuclide observed at ground level. For most practical circumstances the activity concentrations of ${ }^{214} \mathrm{Bi}$ and ${ }^{214} \mathrm{~Pb}$ were found to be close to the EEDC of the actual mixture of ${ }^{222} \mathrm{Rn}$ and short-lived decay products in outdoor air, a finding which is only slightly dependent on the actual equilibrium ratio, $\mathrm{E}_{\mathrm{p}}{ }^{(12,13)}$. The EEDC, a quantity defined to express the inhalation dose of ${ }^{222} \mathrm{Rn}$ progeny ${ }^{(18)}$ (which is dominated by the potential $\alpha$ energy of inhaled particles), is thus also an appropriate parameter to estimate the amount of $\gamma$ radiation emitted by ${ }^{222} \mathrm{Rn}$ progeny in outdoor air.

Under 'dry' conditions the natural ambient dose rate, $\dot{\mathrm{H}}_{\mathrm{DR}}^{*}$, may thus be approximated by:

$$
\begin{aligned}
\dot{\mathrm{H}}_{\text {DRY }}^{*}(\mathrm{t}) & \approx\left[\dot{\mathrm{H}}_{\mathrm{COS}}^{*}+\dot{\mathrm{H}}_{\mathrm{TER}}^{*}\right]+\Delta \dot{\mathrm{H}}_{\mathrm{COS}}^{*}(\mathrm{t})+\dot{\mathrm{H}}_{\text {AIR }}^{*}(\mathrm{t}) \\
& \approx \mathrm{C}_{\mathrm{o}}+\mathrm{C}_{\mathrm{p}}\left[\mathrm{p}(\mathrm{t})-\mathrm{p}_{\mathrm{o}}\right]+\mathrm{C}_{\mathrm{EEDC}} \times \operatorname{EEDC}(\mathrm{t})
\end{aligned}
$$

The parameter $C_{0}$ represents the sum of the (timeaveraged) cosmogenic dose rate at $1013 \mathrm{hPa}\left(\sim 40 \mathrm{nSv} \cdot \mathrm{h}^{-1}\right.$ at sea level, when expressed in ambient dose rate $(1,5,9,13,20,21)$ and the time-averaged but location-dependent terrestrial dose rate, the latter including the influence of nearby constructions. Values of $\mathrm{C}_{\mathrm{o}}$ generally fall in the range $50-120 \mathrm{nSv} \cdot \mathrm{h}^{-1}$ in the Netherlands ${ }^{(5,13)}$. There is a slight dependence on measuring height ${ }^{(16)}$.

Linear regression analysis was used to evaluate the validity of Equation 2 and to obtain values for the proposed parameters. Assuming the parameters $\mathrm{C}_{0}, \mathrm{C}_{\mathrm{p}}$ and $\mathrm{C}_{\mathrm{EEDC}}$ to be constant within the considered time interval, single analysis runs were performed on selected hourly recordings from one month, with typically over 500 data 'pairs' meeting the selection criteria, yielding best values and uncertainty ranges for each parameter. Figure $1(\mathrm{a}-\mathrm{c})$ shows the results obtained from the NRM location Bilthoven (627) (ambient dose rate and EEDC, independently measured) and the KNMI station De Bilt (air pressure) about $2 \mathrm{~km}$ away. Data from other locations and time periods were used to validate the results.

This approach requires the influence of each radiation source on the ambient dose rate to be uncorrelated. In fact, a weak non-linear correlation between air pressure and EEDC was found to be present, which may manifest itself more strongly during specific weather episodes. However, within the $\pm 2 \sigma$ air pressure variation band (covering $95 \%$ of the observations) this correlation was shown to be very weak and may be completely discarded $^{(13)}$.

\section{The adjusted natural background}

The mean values of $\mathrm{C}_{\mathrm{o}}$ found for Bilthoven (627) in 1990 and 1994 were 73.1 and 73.7 nSv.h ${ }^{-1}$, respectively. Monthly values as displayed in Figure 1(a) show that this background level varies over about $\pm 1 \mathrm{nSv}$. $\mathrm{h}^{-1}$, with lower values in the late spring and higher values in the winter. The observed variations, which are small but statistically significant, reflect the influence of minor processes (e.g. variations in the topsoil radon profile) not explicitly accounted for in Equation 2. Sensitivity of equipment to ambient temperature can be excluded as a probable cause ${ }^{(13)}$. Residual variations will be discussed again later on.

\section{Dose rate dependence on air pressure}

The relationship between ambient dose rate and air pressure is assumed to be linear, at least within the range of variations as observed at ground level in the Netherlands. This hypothesis was found to be correct after examining residuals (i.e. observed values minus fitted values), plotted as a function of air pressure, and by evaluating the effect of introducing a quadratic air pressure term in Equation 2.

The mean value of $\mathrm{C}_{\mathrm{p}}$ found for Bilthoven (627) in 1990 and 1994 equals $-0.120 \mathrm{nSv} \cdot \mathrm{h}^{-1} \cdot \mathrm{hPa}^{-1}$ (95\% CI: -0.114 to $\left.-0.126 \mathrm{nSv} \cdot \mathrm{h}^{-1} \cdot \mathrm{hPa}^{-1}\right) . \mathrm{C}_{\mathrm{p}}$ values determined for other locations match this value. We assume that the minor variations observed in the monthly data (Figure 1(b)) are mainly due to deficiencies in the test (for instance, the presence of some perturbed data or some 'incidental' correlation between air pressure and airborne radioactivity) and that this parameter can, indeed, be regarded as a constant, provided that the cosmogenic source strength remains constant. Variations in ambient dose rate due to air pressure fluctuations can thus be assessed fairly precisely using $\mathrm{C}_{\mathrm{p}}=-0.120 \mathrm{nSv} \cdot \mathrm{h}^{-1} \cdot \mathrm{hPa}^{-1}$, with a $1 \sigma$ uncertainty of $0.003 \mathrm{nSv} \cdot \mathrm{h}^{-1} \cdot \mathrm{hPa}^{-1}$. The value presented here agrees with values reported in the literature ${ }^{(21,22)}$, but has a comparatively low uncertainty.

Ambient dose rates are thus expected to vary with- 

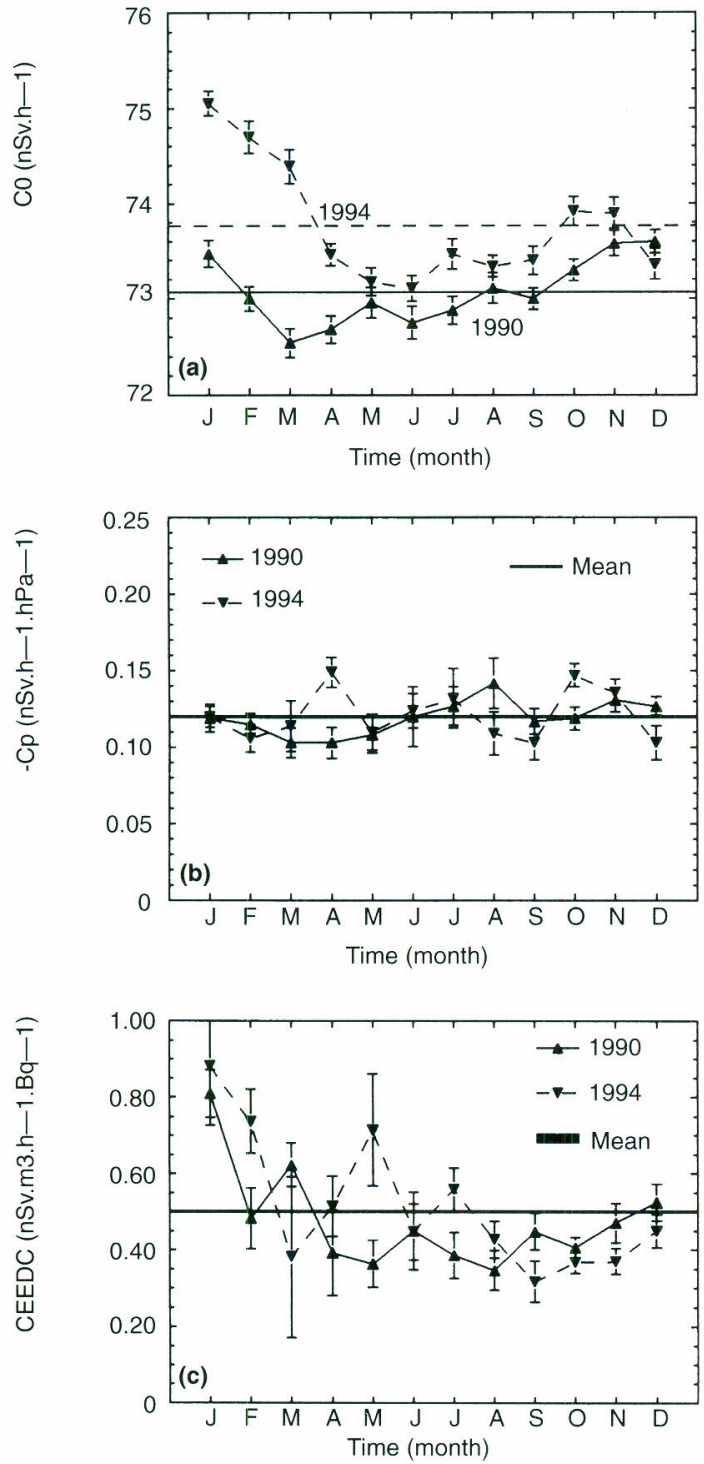

Figure 1. Parameter values, including $1 \sigma$ error bars, obtained from a sequence of statistical analyses on monthly time series (hourly data) for two separate years. Radiometric data were taken from NRM location Bilthoven (627), and meteorological data from KNMI station De Bilt. (a) Monthly results for the compensated background of ambient dose rate, $\mathrm{C}_{0}$, showing relative variations of a few per cent. NRM equipment was moved over a short distance in the course of 1993, explaining part of the systematic difference between 1990 and 1994. (b) Monthly results for $\mathrm{C}_{\mathrm{p}}$, describing the influence of air pressure on the ambient dose rate. This parameter is considered to be a constant with a value of $-0.120 \pm 0.003 \mathrm{nSv} \cdot \mathrm{h}^{-1} \cdot \mathrm{hPa}^{-1}$ (c) Monthly results for $\mathrm{C}_{\mathrm{EEDC}}$, showing the influence of airborne ${ }^{222} \mathrm{Rn}$ progeny (expressed in EEDC) on the ambient dose rate. $\mathrm{C}_{\mathrm{EEDC}}$, with a mean value of $0.50 \mathrm{nSv} \cdot \mathrm{h}^{-1} \cdot \mathrm{Bq}^{-1} \cdot \mathrm{m}^{3}$, exhibits a seasonal effect, reflecting the difference in typical air profiles of ${ }^{222} \mathrm{Rn}$ (progeny) in summer and winter periods. in a range of approximately $10 \mathrm{nSv} \cdot \mathrm{h}^{-1}$ due to air pressure variations.

\section{Dose rate dependence on airborne ${ }^{222} \mathrm{Rn}$ progeny}

The trend in monthly values for $\mathrm{C}_{\mathrm{EEDC}}$, as plotted in Figure 1(c), shows the values to be relatively high in winter and lower in summer and autumn; it is obvious that this parameter cannot be regarded as a pure constant. There are two factors which may explain the observed variation. First, the ambient dose rate corresponding to a certain EEDC level depends slightly on the equilibrium factor $E_{p}$. By computing theoretical values derived from the so-called 'Jacobi' model ${ }^{(18)}$, this effect was shown to explain a variation in the parameter $\mathrm{C}_{\mathrm{EEDC}}$ of plus or minus $5 \%$ at most. The observed variation is, however, larger.

The second factor influencing the actual value of this parameter stems from variations in the vertical ${ }^{222} \mathrm{Rn}$ (daughter) profile in air. This profile is strongly influenced by atmospheric stability. At normal and strong turbulence the vertical ${ }^{222} \mathrm{Rn}$ profile is virtually constant for altitudes up to $1 \mathrm{~km}^{(23)}$ and the assumption of a uniform semi-infinite cloud of short-lived ${ }^{222} \mathrm{Rn}$ decay products is valid. When strong temperature inversion is present, this assumption is not valid any more and the measured ambient dose rate per unit EEDC measured at ground level will be less than under normal or strong turbulence due to the change in the vertical profile. It is thus expected that $\mathrm{C}_{\text {EEDC }}$ values determined during inversion will be lower. Strong temperature inversion often arises in late summer evenings and disappears at sunrise ${ }^{(8,13)}$. To examine the influence of this process, the Bilthoven 1990 data of May, June, July and August were combined and the parameter $\mathrm{C}_{\text {EEDC }}$ was determined for 'daytime' and 'night-time' hours, yielding a 'daytime' value of $0.48 \pm 0.03(1 \sigma) \mathrm{nSv} \cdot \mathrm{h}^{-1} \cdot \mathrm{Bq}^{-1} \cdot \mathrm{m}^{3}$ and a lower 'night-time' value of $0.38 \pm 0.02(1 \sigma)$ $\mathrm{nSv} \cdot \mathrm{h}^{-1} \cdot \mathrm{Bq}^{-1} \cdot \mathrm{m}^{3}$, conforming to expectations. The latter value is almost equal to the value based on all data, due to the fact that EEDC summer levels at ground level are, because of inversion, considerably higher during the night, so night situations dominate the results of the linear regression analysis. The 'daytime' $\mathrm{C}_{\mathrm{FEDC}}$ summer value is close to the 'all-day' values found during spring and in December when strong vertical mixing is expected. $\mathrm{C}_{\text {EEDC }}$ values found for January, and to a lesser extent, February, are relatively high. The reason for this is not yet clear but it might be related to the aerosol spectrum present in the $\operatorname{air}^{(24)}$ or meteorological conditions both being different in winter.

It is concluded that the time-varying contribution of airborne ${ }^{222} \mathrm{Rn}$ progeny to the ambient dose rate can be approximated by the linear relationship as proposed in Equation 2, but the result carries a relatively large uncertainty, of the order of some $20 \%(1 \sigma)$, due to varying environmental conditions not accounted for in the description. For unspecified conditions a proportionality 
factor, $\mathrm{C}_{\text {EEDC }}$, equal to $0.50 \mathrm{nSv} \cdot \mathrm{h}^{-1} \cdot \mathrm{Bq}^{-1} \cdot \mathrm{m}^{3}$, with an approximate uncertainty $(1 \sigma)$ of $0.10 \mathrm{nSv} \cdot \mathrm{h}^{-1} \cdot \mathrm{Bq}^{-1} \cdot \mathrm{m}^{3}$ is proposed. This value compares with a calculated value of $0.40 \mathrm{nSv} \cdot \mathrm{h}^{-1} \cdot \mathrm{Bq}^{-1} \cdot \mathrm{m}^{3} \quad\left(\mathrm{E}_{\mathrm{p}}=0.7\right)$, based on energydependent dose rate coefficients for submersion in a semi-infinite cloud $^{(25)}$.

On the average, outdoor EEDC levels in the Netherlands are low, of the order of $1-2 \mathrm{~Bq} \cdot \mathrm{m}^{-3(13)}$, but much higher values have been observed during specific weather episodes, on rare occasions even up to $50 \mathrm{~Bq} \cdot \mathrm{m}^{-3}$. One may therefore expect dose rate contributions to be in a range of $0-25 \mathrm{nSv} \cdot \mathrm{h}^{-1}$. However, extreme EEDC values are generally associated with a rapidly decreasing vertical ${ }^{222} \mathrm{Rn}$ profile; in such cases the ambient dose rate as calculated by Equation 2 will overestimate the actual situation. Nevertheless, dose rate contributions from airborne ${ }^{222} \mathrm{Rn}$ progeny may occasionally exceed $10 \mathrm{nSv} \cdot \mathrm{h}^{-1}$

Monitoring data are often provided as average values per time interval $\mathrm{k}$, where the intervals are separated by a fixed time period $\mathrm{T}$ (e.g. $10 \mathrm{~min}$ or $1 \mathrm{~h}$ ). When the parameters $\mathrm{C}_{\mathrm{o}}, \mathrm{C}_{\mathrm{p}}$ and $\mathrm{C}_{\mathrm{EEDC}}$ are assumed to be constant, the ambient dose rate (dry periods) averaged over time interval $\mathrm{k},\left\langle\dot{\mathrm{H}}_{\mathrm{DRY}}^{*}\right\rangle_{\mathrm{k}}$, is approximated by:

$$
\left\langle\dot{\mathrm{H}}_{\mathrm{DRY}}^{*}\right\rangle_{\mathrm{k}} \approx \mathrm{C}_{\mathrm{o}}+\mathrm{C}_{\mathrm{p}}\left[\langle\mathrm{p}\rangle_{\mathrm{k}}-\mathrm{p}_{\mathrm{o}}\right]+\mathrm{C}_{\mathrm{EEDC}} \times\langle\mathrm{EEDC}\rangle_{\mathrm{k}}
$$

with $\langle p\rangle_{k}$ the average air pressure and $\langle E E D C\rangle_{k}$ the average EEDC in the corresponding time interval. Equation 3 can be used for any value for $\mathrm{T}$, thus also for time periods of a month or a year. The notation introduced here will also be used in the evaluation of the influence of rainfall on the ambient dose rate.

\section{Stage 2: Washout and rainout of ${ }^{222} \mathrm{Rn}$ progeny}

Rainfall has a relatively large impact on the variations observed in ambient dose rate. Short-lived decay products of ${ }^{222} \mathrm{Rn}$ are caught during raindrop formation in cloud (washout) or scavenged from the atmosphere under cloud (rainout), where the first process is dominant $^{(6,26)}$. Wet deposition therefore results in a short-lived ground surface activity, increasing the ambient dose rate due to $\gamma$ emission from primarily ${ }^{214} \mathrm{Bi}$ and, to a lesser extent, ${ }^{214} \mathrm{~Pb}$.

Mechanisms of particle washout, in general and related to radioactivity, have been studied extensively ${ }^{(6,7,26,27)}$. Complex models are proposed to describe this process for ${ }^{222} \mathrm{Rn}$ progeny in detail ${ }^{(6)}$, but reliable values for the many parameters used as input are generally lacking. By using a simplified model, demanding just a few but readily available input parametres, one may end up with a similar uncertainty in the calculated value. Takeuchi and Katase identified the ${ }^{222} \mathrm{Rn}$ concentration at ground level and the deposition rate as the most important parameters for the description of elevated radiation levels ${ }^{(6)}$

Using average parameter values for calculating the ambient dose rate during dry periods (Equation 2), esti- mates were made for the dose rate contribution due to rainfall by subtracting the calculated 'dry' component from the measured one. Based on the complete set of data pairs obtained in 1990, (average) values were determined to reveal the influence of the deposition rate during the current and previous hours on the ambient dose rate (Figure 2).

The observed data agree with calculations obtained from a simple deposition model, assuming uniform rainfall for one hour with fixed concentrations of ${ }^{222} \mathrm{Rn}$ progeny in rainwater. This model was derived as follows. The contribution from deposited ${ }^{222} \mathrm{Rn}$ progeny to the ambient dose rate, $\dot{\mathrm{H}}_{\mathrm{DEP}}^{*}(\mathrm{t})$, is in general written as:

$$
\dot{\mathrm{H}}_{\text {DEP }}^{*}(\mathrm{t})=\sum_{\mathrm{i}=2}^{3} \mathrm{~K}_{\mathrm{i}} \mathrm{A}_{\mathrm{i}}(\mathrm{t})=\sum_{\mathrm{i}=2}^{3} \mathrm{~K}_{\mathrm{i}} \lambda_{\mathrm{i}} \mathrm{N}_{\mathrm{i}}(\mathrm{t})
$$

with $\mathrm{A}_{\mathrm{i}}(\mathrm{t})$ and $\mathrm{N}_{\mathrm{i}}(\mathrm{t})$ the time-varying surface activity $\left(\mathrm{Bq} \cdot \mathrm{m}^{-2}\right)$ and particle density $\left(\mathrm{m}^{-2}\right)$ of ${ }^{214} \mathrm{~Pb}(\mathrm{i}=2)$ and ${ }^{214} \mathrm{Bi}(\mathrm{i}=3)$, respectively, $\lambda_{\mathrm{i}}$ their half-lives and $\mathrm{K}_{\mathrm{i}}$ the nuclide-specific coefficients for the conversion of surface activity to ambient dose rate. Values for $\mathrm{K}_{\mathrm{i}}$ were taken from the dose rate model Soil- $\operatorname{Rad}^{(16)}$, using a plane geometry with an active surface radius of $300 \mathrm{~m}$, an effective screening thickness of $1 \mathrm{~mm}$ (to take account of the roughness of the soil surface) and a sampling height of $3.5 \mathrm{~m}$, yielding $\mathrm{K}_{2}=1.2 \times$ $10^{-3} \mathrm{nSv} \cdot \mathrm{h}^{-1} \cdot \mathrm{Bq}^{-1} \cdot \mathrm{m}^{2}$ and $\mathrm{K}_{3}=5.2 \times 10^{-3} \mathrm{nSv} \cdot \mathrm{h}^{-1}$. $\mathrm{Bq}^{-1} \cdot \mathrm{m}^{2}$. The particle density functions $\mathrm{N}_{\mathrm{i}}(\mathrm{t})$ are the nuclide-specific solutions to the differential equations and boundary conditions describing the build-up (due to deposition), ingrowth and decay of ${ }^{222} \mathrm{Rn}$ progeny $(i=1,2,3,4)$ on the ground surface. These equations are

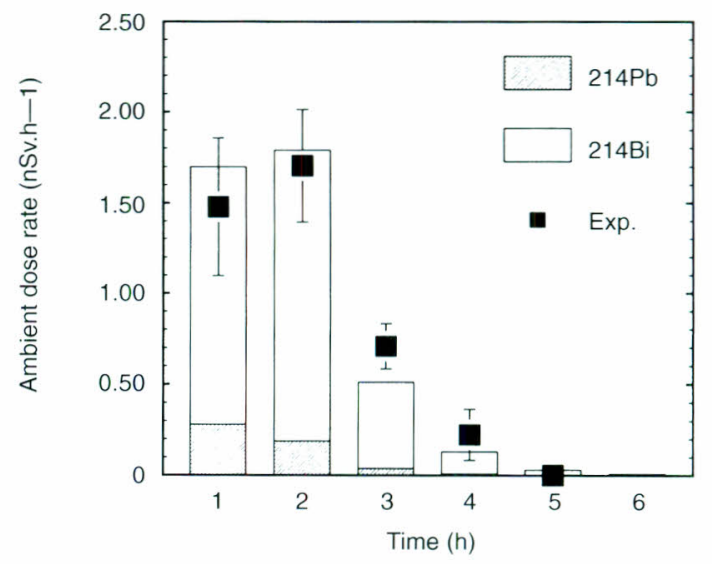

Figure 2. Comparison of measured (symbols, with $1 \sigma$ error bars) and calculated (bars) dose rate elevations following $1 \mathrm{~mm}$ of rainfall in the first hour. The measured data represent average values based on one year of observation (Bilthoven (627), 1990). The calculated data are obtained from the model described, assuming a uniform precipitation rate of $1 \mathrm{~mm} \cdot \mathrm{h}^{-1}$ and a fixed activity concentration of ${ }^{214} \mathrm{Bi}$ in rainwater of $6.5 \times 10^{5} \mathrm{~Bq} . \mathrm{m}^{-3}$. 
very similar to the well-known Bateman equations and are not elaborated here.

Now consider one time period of rainfall with fixed duration, T, yielding a constant deposition rate for ${ }^{214} \mathrm{Bi}$ equal to $1 \mathrm{~Bq} \cdot \mathrm{m}^{-2} \cdot \mathrm{s}^{-1}$ : This deposition rate is the product of the rainfall rate, $\dot{\Phi}\left(\mathrm{m} \cdot \mathrm{s}^{-1}\right)$ and the activity concentration of ${ }^{214} \mathrm{Bi}$ in rainwater, denoted as $\mathrm{a}_{3 \text { rain }}\left(\mathrm{Bq} \cdot \mathrm{m}^{-3}\right)$. Assume further fixed ratios between the various concentrations of nuclides in rainwater reaching the earth. These ratios were taken from Minato ${ }^{(7)}$ : relative to ${ }^{214} \mathrm{Bi}$ the concentrations of ${ }^{218} \mathrm{Po}$ and ${ }^{214} \mathrm{~Pb}$ were set equal to 0.035 and 0.930 , respectively. Under these assumptions the ingrowth and decay of particles following one 'deposition unit' of ${ }^{22} \mathrm{Rn}$ progeny to the ground surface was calculated by solving the corresponding differential equations. The average contribution to the ambient dose rate in time period $n,\left\langle\dot{\mathrm{H}}_{\mathrm{U}}^{*}\right\rangle_{\mathrm{n}}$, following from a homogenous surface activity growth of $1 \mathrm{~Bq} \cdot \mathrm{m}^{-2} \cdot \mathrm{s}^{-1}$ during time interval $n=1$, is then calculated as:

$$
\left\langle\dot{\mathrm{H}}_{\mathrm{U}}^{*}\right\rangle_{\mathrm{n}}=\sum_{\mathrm{i}=2}^{3} \mathrm{~K}_{\mathrm{i}} \frac{\lambda_{\mathrm{i}}}{\mathrm{T}} \int_{(\mathrm{n}-1) \mathrm{T}}^{\mathrm{nT}} \mathrm{N}_{\mathrm{i}}(\mathrm{t}) \mathrm{dt}(\mathrm{n} \geqslant 1)
$$

With half-lives $<0.5 \mathrm{~h}$ the ambient dose rate will drop to an unnoticeable level within five hours; ambient dose rates for time periods exceeding $\mathrm{n}=\mathrm{N}$, with $\mathrm{N}$ equal to $5 \mathrm{~h} / \mathrm{T}$, can thus be disregarded. Values for $\left\langle\dot{\mathrm{H}}_{\mathrm{U}}\right\rangle_{\mathrm{n}}$, calculated for the case $T=3600 \mathrm{~s}$ and $\mathrm{T}=600 \mathrm{~s}$, are given in Table 1. The total ambient dose following one hour of rainfall, with parameters as given above, equals $23 \mathrm{nSv}$.

The ambient dose rate following the deposition of ${ }^{222} \mathrm{Rn}$ progeny is linearly proportional to the actual deposition rate, i.e. the product of precipitation rate and the activity concentration in rainwater. By assuming fixed activity concentrations in rainwater in the same ratios as used above, we find that calculated and measured ambient dose rates (Bilthoven $(627), 1990)$ match in number when $\mathrm{a}_{3 \text { rain }}$ is set equal to $6.5 \times 10^{5} \mathrm{~Bq} \cdot \mathrm{m}^{-3}$ (Figure 2). Calculated and experimental data both show that due to the ingrowth of ${ }^{214} \mathrm{Bi}$ the ambient dose rate reaches its maximum value after the rain has stopped. Based on the 1990 data set, we find a time-integrated ambient dose per $\mathrm{mm}$ precipitation of $4.1 \mathrm{nSv}$ on average, with an estimated uncertainty
$(1 \sigma)$ of $5 \%$. Approximately $89 \%$ of the dose is due to ${ }^{214} \mathrm{Bi}$ and about $11 \%$ to ${ }^{214} \mathrm{~Pb}$.

To estimate the dose rate elevation in time interval $k$ due to an arbitrary rainfall pattern, we have to include the actual deposition rate of ${ }^{214} \mathrm{Bi}$ in the preceding time intervals $\mathrm{k}+1-\mathrm{n}(1 \leqslant \mathrm{n} \leqslant \mathrm{N})$. This is the product of the precipitation rate, $\langle\dot{\Phi}\rangle_{k+1-n}$ and the activity concentration of ${ }^{214} \mathrm{Bi}$ in rainwater, $\left\langle\mathrm{a}_{3 \text { rain }}\right\rangle_{k+1-n}$, so:

$$
\left\langle\dot{\mathrm{H}}_{\mathrm{DEP}}^{*}\right\rangle_{\mathrm{k}} \approx \sum_{\mathrm{n}=1}^{\mathrm{N}}\langle\dot{\Phi}\rangle_{\mathrm{k}+1-\mathrm{n}} \times\left\langle\mathrm{a}_{3 \mathrm{rain}}\right\rangle_{\mathrm{k}+1-\mathrm{n}} \times\left\langle\dot{\mathrm{H}}_{\mathrm{U}}^{*}\right\rangle_{\mathrm{n}}
$$

However, values for $\left\langle\mathrm{a}_{3 \mathrm{rain}}\right\rangle_{\mathrm{k}+1-n}$ are not readily available so approximated values have to be used. Three different approximations were tried out on a set of 36 experimental rain shower data, obtained from Bilthoven (627) in 1994 and 1995.

The most rigid approximation is to consider this value to be a constant, i.e. $\left\langle a_{3 \text { rain }}\right\rangle_{k+1-n}=a_{3 \text { rain. }}^{\text {fixed }}$. Scale factors, defined as the rain shower-dependent ratio between measured and calculated data, were determined for 36 rain shower data and show variations within a factor of 30 (Figure 3(a)). By forcing the median value of these ratios to 1.0 , we derived a value of $7.1 \times 10^{5} \mathrm{~Bq} . \mathrm{m}^{-3}$ for $\mathrm{a}_{3 \text { rain }}^{\text {fixed }}$ this was $9 \%$ higher than the value derived from the 1990 analysis (Figure 2). Moreover, these ratios increase, on the average, with increasing EEDC, indicating a (positive) correlation between the concentration of ${ }^{222} \mathrm{Rn}$ progeny in rainwater and in surface air. This kind of correlation is more often observed, for instance, in the case of fallout products like ${ }^{137} \mathrm{Cs}$ and ${ }^{90} \mathrm{Sr}^{(27)}$, and it is common to estimate the specific activity of (artificial) radionuclides in rainwater by multiplying the activity concentration in air, measured at ground level, by a so-called washout factor, W, defined as the activity per unit volume rain divided by the activity per unit volume surface air ${ }^{(27)}$. The linear washout factor approach was also applied to the deposition of ${ }^{222} \mathrm{Rn}$ progeny, making use of the fact that, for a large range of equilibrium factors, $E_{p}$, the EEDC is a good measure of the airborne concentration of ${ }^{214} \mathrm{Bi}$. Washout factors were determined for the same set of rain showers

Table 1. Calculated $\dagger$ values of $\left\langle\dot{\mathrm{H}}_{\mathrm{V}}^{*}\right\rangle_{\mathrm{n}}$ (in $\mathrm{nSv} \cdot \mathrm{h}^{-1}$ ), assuming a uniform deposition rate for ${ }^{214} \mathrm{Bi} \neq$ of $1 \mathrm{~Bq} \cdot \mathrm{m}^{-2} \cdot \mathrm{s}^{-1}$ during

\begin{tabular}{|c|c|c|c|c|c|c|c|c|c|c|c|c|c|}
\hline 1 & 9.14 & 1 & 1.85 & 6 & 1.85 & 11 & 0.65 & 16 & 0.20 & 21 & 0.06 & 26 & 0.02 \\
\hline 2 & 9.87 & 2 & 3.46 & 7 & 1.52 & 12 & 0.52 & 17 & 0.16 & 22 & 0.05 & 27 & 0.01 \\
\hline 3 & 2.84 & 3 & 3.06 & 8 & 1.24 & 13 & 0.41 & 18 & 0.13 & 23 & 0.04 & 28 & 0.01 \\
\hline
\end{tabular}
the first time interval $(n=1)$.

†Using $\mathrm{K}_{2}=1.2 \times 10^{-3} \mathrm{nSv} \cdot \mathrm{h}^{-1} \cdot \mathrm{Bq}^{-1} \cdot \mathrm{m}^{2}$ and $\mathrm{K}_{3}=5.2 \times 10^{-3} \mathrm{nSv} \cdot \mathrm{h}^{-1} \cdot \mathrm{Bq}^{-1} \cdot \mathrm{m}^{2}$, derived for a measuring height of $3.5 \mathrm{~m}$. †Deposition rate ${ }^{218} \mathrm{Po}$ : $0.035 \mathrm{~Bq} \cdot \mathrm{m}^{-2} \cdot \mathrm{s}^{-1}$; deposition rate ${ }^{214} \mathrm{~Pb}: 0.930 \mathrm{~Bq} \cdot \mathrm{m}^{-2} \cdot \mathrm{s}^{-1}$. 
as mentioned above, yielding values between $2.1 \times 10^{5}$ and $5.5 \times 10^{6}$, with a medium value, $\mathrm{W}_{\text {median }}=8.0 \times$ $10^{5}$. The latter value is $30-35 \%$ higher than typical values reported for ${ }^{137} \mathrm{Cs}^{(27)}$. Washout factors were found to be independent of the precipitation volume. Based on these results, Equation 6 can be simplified to:

$$
\begin{aligned}
\left\langle\dot{\mathrm{H}}_{\text {DEP }}^{*}\right\rangle_{\mathrm{k}} \approx & \mathrm{W}_{\text {median }} \sum_{\mathrm{n}=1}^{\mathrm{N}}\langle\dot{\Phi}\rangle_{\mathrm{k}+1-\mathrm{n}} \\
& \times\langle\text { EEDC }\rangle_{\mathrm{k}+1-\mathrm{n}} \times\left\langle\dot{\mathrm{H}}_{\mathrm{U}}^{*}\right\rangle_{\mathrm{n}}
\end{aligned}
$$

where we approximated the actual value for $\mathrm{W}$ by the median value found above. Note that $\mathrm{W}_{\text {median }}$ can also be written as:

$$
\mathrm{W}_{\text {median }}=\frac{\mathrm{a}_{3 \mathrm{rain}}^{\text {fixed }}}{\text { EEDC }_{\mathrm{o}}^{\text {linear }}}
$$

with $\mathrm{EEDC}_{\mathrm{o}}^{\text {linear }} \approx 0.9 \mathrm{~Bq} \cdot \mathrm{m}^{-3}$.

The ratios between measured and calculated data, the latter based on the linear approximation of $\left\langle\mathrm{a}_{3 \mathrm{rain}}\right\rangle_{k+1-n}$ with $\langle\text { EEDC }\rangle_{k+1-n}$ as given by Equation 7, were determined for the 36 rain showers mentioned above and are given in Figure 3(b). It shows that, in comparison with Figure 3(a), the distribution of these ratios is now sharper around unity, implying that the uncertainty in the calculated values is less than in the case of the 'fixed-value' approach. On the other hand, the ratios in the 'linear' approach still show a trend when plotted
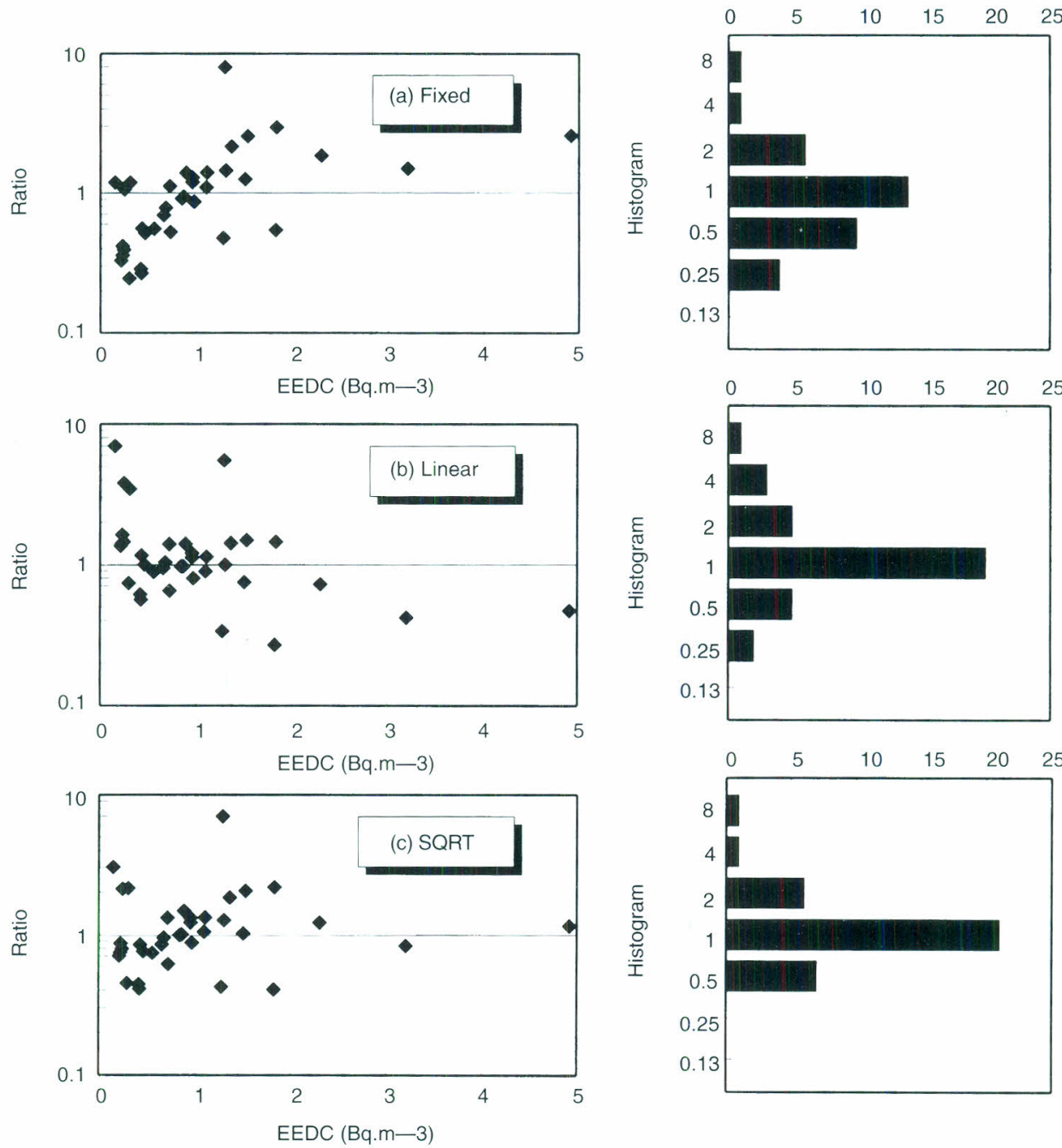

Figure 3. Rain-shower specific ratios between measured and calculated contributions of deposited ${ }^{222} \mathrm{Rn}$ progeny to the ambient dose rate, using different approximations for the specific activity of ${ }^{214} \mathrm{Bi}$ in rainwater $(\mathrm{a}-\mathrm{c}$, see text). Results are shown on logarithmic scales as a function of EEDC (left) and as histograms (right). Radiological and meteorological data were collected at Bilthoven (627) in 1994 and 1995. 
against EEDC, now decreasing with increasing EEDC. This finding may be explained by the fact that higher than average EEDC values are often associated with a non-uniform vertical ${ }^{222} \mathrm{Rn}$ profile, caused by local exhalation under stable atmospheric conditions. Under such circumstances, the concentration of ${ }^{222} \mathrm{Rn}$ (progeny) at ground level may be significantly higher than at cloud height and the linear washout factor approach may no longer work well.

To get a better handle on this problem, an empirical relation was tried out to estimate the concentration of ${ }^{214} \mathrm{Bi}$ in rainwater. This relation holds in between the 'fixed' and 'linear' approach as evaluated above. Using a notation analogous to the one introduced in Equation 8 , the following equation is proposed to estimate the elevation of the ambient dose rate in time interval $\mathrm{k}$ :

$$
\begin{aligned}
&\left\langle\dot{\mathrm{H}}_{\text {DEP }}^{*}\right\rangle_{k} \approx \frac{\mathrm{a}_{\text {rain }}^{\text {fixed }}}{\sqrt{\left(\text { EEDC }_{\mathrm{o}}^{\mathrm{SQRT}}\right)}} \\
& \sum_{\mathrm{n}=1}^{\mathrm{N}}\langle\dot{\Phi}\rangle_{\mathrm{k}+1-\mathrm{n}} \sqrt{\left(\langle\text { EEDC }\rangle_{k+1-n}\right)\left\langle\dot{\mathrm{H}}_{\mathrm{U}}^{*}\right\rangle_{\mathrm{n}}}
\end{aligned}
$$

A comparison of measured and calculated data based on this 'square root (SQRT)' approach is provided in
Figure 3(c). The median value of the corresponding ratios equals unity when $\mathrm{EEDC}_{\mathrm{o}}^{\mathrm{SQRT}}=1.0 \mathrm{~Bq} \cdot \mathrm{m}^{-3}$. All ratios but one fall in the range $0.32-3.2$. Moreover, the scattering of data around unity does not depend on EEDC any more. This is, in particular, important for the assessment of elevated ambient dose rate in periods when the EEDC is relatively high because extreme effects of rainfall are often observed under such conditions.

Figure 4 compares the calculated ambient dose rate, based on Equations 3 and 9, and the actual measured ambient dose rate, showing good agreement. From the three approximations evaluated, the 'SQRT' approach was also found out to give the best results when applied to data sets obtained from other NRM locations, using the same parameter values as derived above.

\section{Stage 3: Residual variations}

The expressions as given in Equations 3 and 9 account for most of the observed variations in the ambient dose rate. These expressions were, however, based on assumptions such as the absence of variations in terrestrial dose rate and in the 'source strength' of cosmic radiation. To examine our assumptions and to look for possible other influential factors, the residual ambient
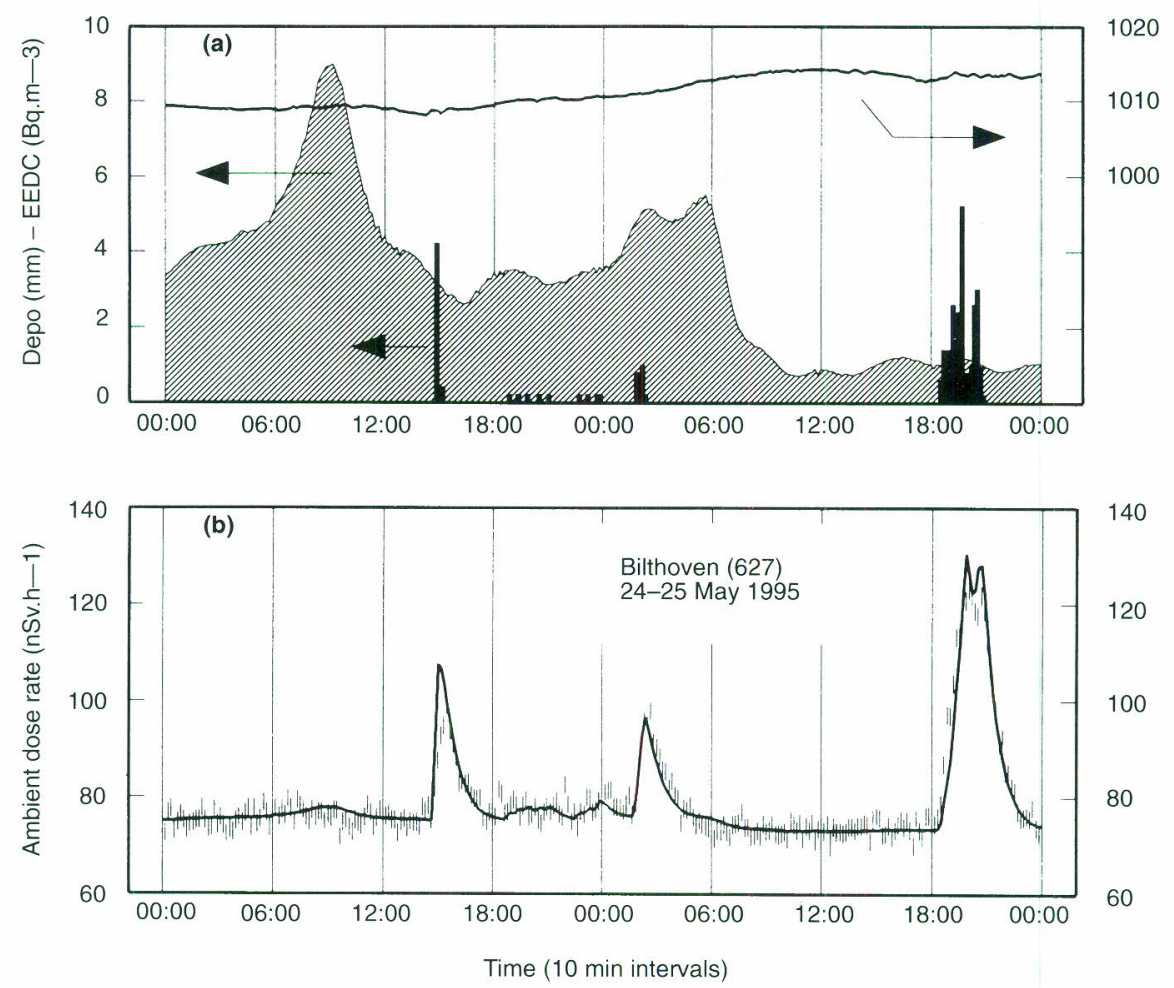

Figure 4. Comparison of measured and calculated (Equations 3 and 9) ambient dose rate elevated due to washout of ${ }^{222} \mathrm{Rn}$ progeny. (a) Time-varying input data. (b) Measured (vertical symbols) and calculated (solid line) ambient dose rate. 
A DYNAMIC COMPENSATION METHOD FOR NATURAL AMBIENT DOSE RATE
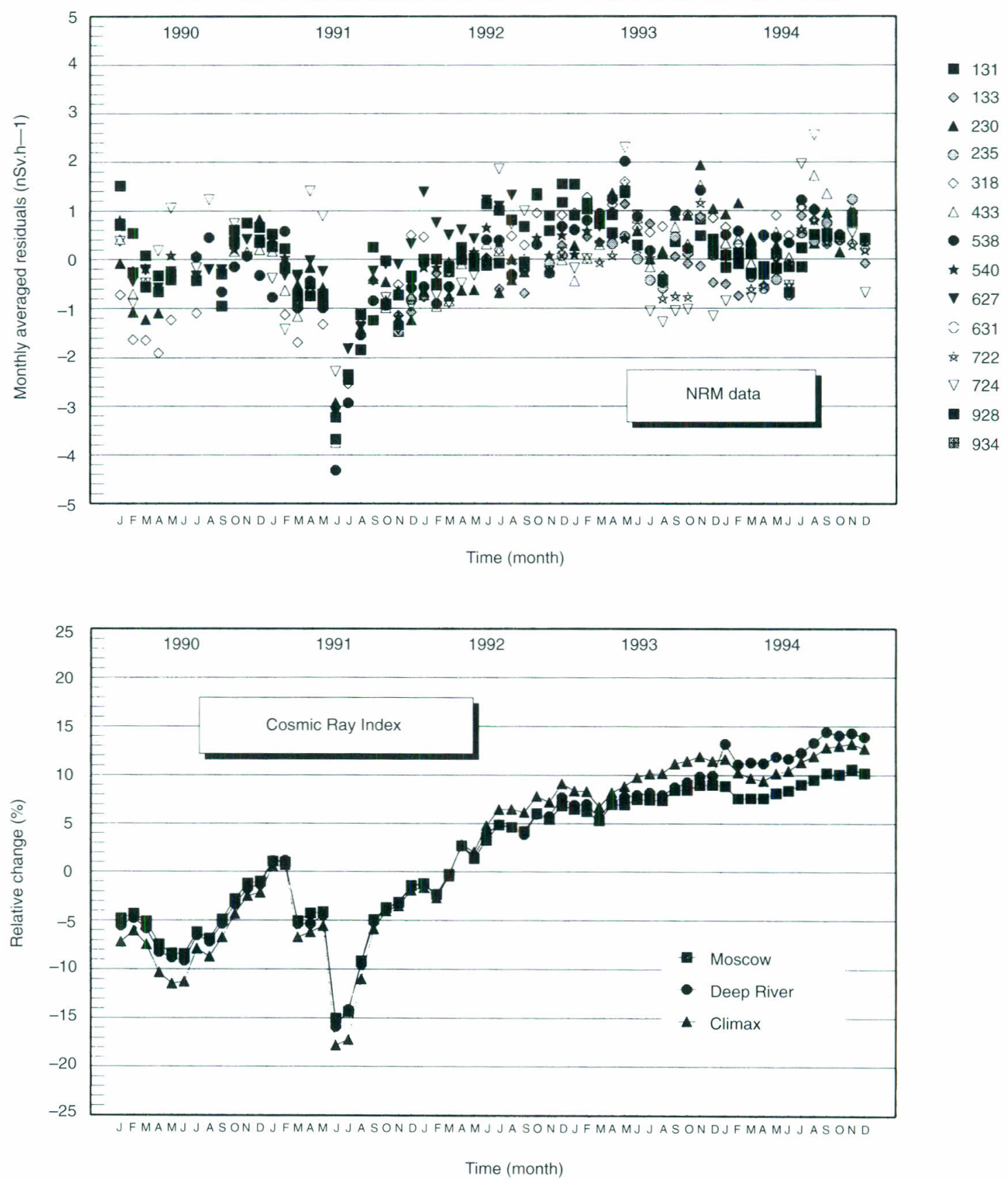

Figure 5. (a) Residual variations in ambient dose rate determined for the 14 principal NRM locations over the period $1990-1994$ Monthly averaged data are compensated for the location-dependent long-term average background and the estimated influence of fluctuations in air pressure, EEDC and precipitation. (b) Relative change in monthly averaged cosmic ray indices recorded in Moscow, Russia (N55, E37, 200 m), Deep River, Canada (N46, W77, 145 m) and Climax, Colorado (N39, W106, 3400 m) ${ }^{(28)}$. 
dose rate was investigated, i.e. measured minus calculated, using average parameter values. On the short-term (hourly values), residual ambient dose rates were found to vary, in general, within $\pm 3 \mathrm{nSv} \cdot \mathrm{h}^{-1}$ (dry periods only), relative to an average ambient dose rate of about $80 \mathrm{nSv} \cdot \mathrm{h}^{-1(13)}$. However, on some occasions (to be illustrated later on) larger deviations were noticed, due to either human practices or rare natural phenomena not accounted for in the description.

To examine the possible long-term trend in the ambient dose rate, monthly averaged residuals were derived, including rainfall effects for all 14 principal NRM stations over a period of five years (see Figure 5(a)). These results may contain uncertainties because the nearest weather station could be as far away as $25 \mathrm{~km}$ from the NRM site. Figure 5(a) shows a similar trend in the residuals for all 14 NRM locations, including an anomalous dip in the summer of 1991. Apart from this dip (apparently due to a temporary decrease in the cosmogenic dose rate at sea level), the remaining variations are generally confined to $\pm 2 \mathrm{nSv} \cdot \mathrm{h}^{-1}$, implying that (slow) variations in the terrestrial dose rate are at least within this range.

Figure 5(b) shows the relative change in cosmic ray indices ${ }^{(28)}$, based on neutron measurements performed at Moscow (Russia), Deep River (Canada) and Climax (Colorado). The patterns observed in both the NRM residuals and the cosmic ray indices are clearly correlated, giving evidence that most of the residual variation
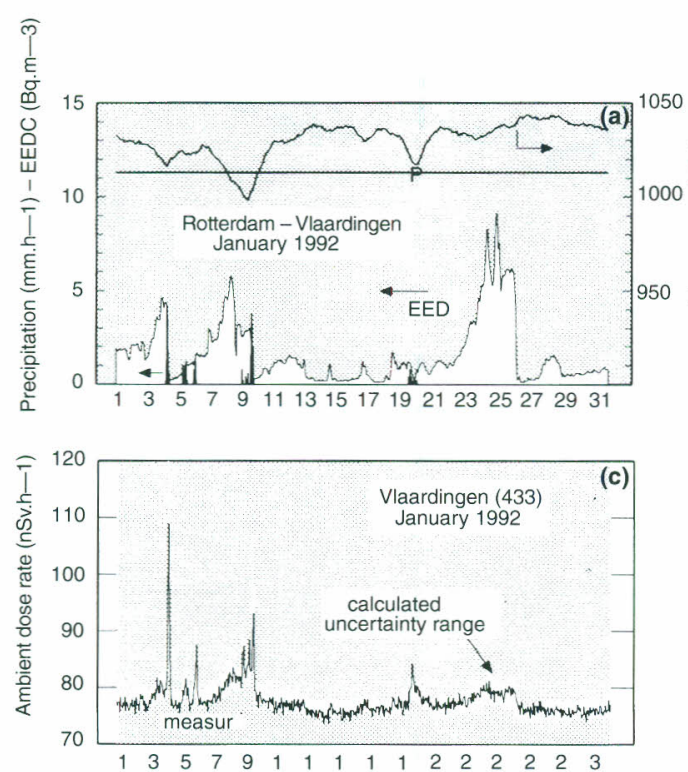

observed in the NRM data is indeed due to variations in the cosmic source strength. The overall increase observed in the cosmic ray indices over the whole period is, however, less obvious in the case of the NRM data, indicating that there is not a one-to-one relation between the intensity of cosmogenic neutrons and the ionising part of the secondary cosmic radiation observed at sea level.

The summer 1991 event was caused by a significant worldwide disturbance of the geomagnetic field hindering galactic particles entering the earth's atmosphere. In the first two weeks of June 1991 two severe geomagnetic storms ( $\mathrm{A}_{\mathrm{p}}^{*}$ index: 196 and 149, respectively) were reported $^{(28)}$. Minor short-term decreases in dose rate residuals (e.g. by the end of March 1991, see Figure 7 below) were found to correlate with geomagnetic storms as well. Geomagnetic storms, a result of solar activities, are affected by the 11-year solar cycle. Cosmic ray indices further show that the decrease in the cosmogenic source strength observed in June 1991 has been unprecedented in, at least, the previous four decades ${ }^{(28)}$.

\section{A DYNAMIC DETECTION METHOD FOR ANOMALIES}

The true ambient dose rate, $\dot{H}^{*}(\mathrm{x}, \mathrm{y}, \mathrm{t})$ can in general be written as:

$$
\dot{\mathrm{H}}^{*}(\mathrm{x}, \mathrm{y}, \mathrm{t})=\dot{\mathrm{H}}_{\mathrm{NAT}}^{*}(\mathrm{x}, \mathrm{y}, \mathrm{t})+\dot{\mathrm{H}}_{\mathrm{EVENT}}^{*}(\mathrm{x}, \mathrm{y}, \mathrm{t})
$$
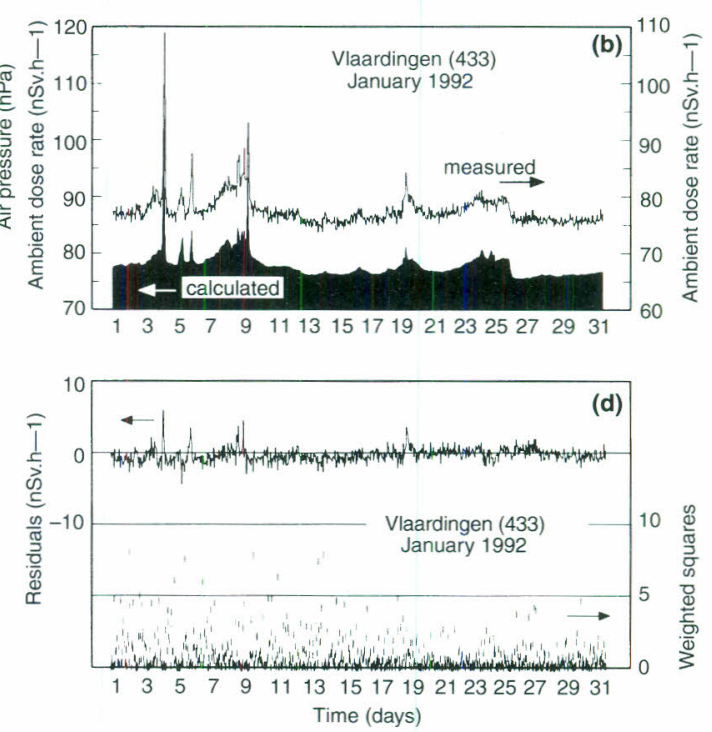

Figure 6. Comparison of a monthly series of measured and calculated hourly ambient dose rates. (a) Time-varying input data (meteorological data were taken from the KNMI weather station Rotterdam, approximately $8 \mathrm{~km}$ away). (b) Measured and calculated best estimates (note the shifted vertical axes). (c) Measured data (black line) compared to the (estimated) $95 \%$ uncertainty range of the calculated natural ambient dose rate (white area). (d) Residuals (black line) and the so-called 'weighted-squares' (scatter) (see Equation 14). 
where $\dot{\mathrm{H}}_{\mathrm{NAT}}(\mathrm{x}, \mathrm{y}, \mathrm{t})$ represents the (undisturbed) natural contribution to the ambient dose rate and $\dot{\mathrm{H}}_{\mathrm{EVENT}}^{*}(\mathrm{x}, \mathrm{y}, \mathrm{t})$ the impact of any anomaly, for instance, a human practice. The latter contribution is normally nil. The question whether or not we are dealing with an event is thus answered by subtracting $\dot{H}_{\mathrm{N}_{\mathrm{AT}}}^{*}(\mathrm{x}, \mathrm{y}, \mathrm{t})$ from $\dot{\mathrm{H}}^{*}(\mathrm{x}, \mathrm{y}, \mathrm{t})$. The problem is that both factors are unknown in practice and can only be estimated.

If we ignore systematic errors in measuring equipment for the moment, a dose rate measurement obtained from time interval $\mathrm{k},\left\langle\dot{\mathrm{H}}_{\mathrm{MEAS}}^{*}\right\rangle_{\mathrm{k}}$, equals the true ambient dose rate (averaged over time interval $\mathrm{k}$ ), $\langle\dot{\mathrm{H}}\rangle_{\mathrm{k}}$, apart from an error due to counting statistics, $\epsilon_{k}$, so:

$$
\left\langle\dot{\mathrm{H}}_{\text {MEAS }}^{*}\right\rangle_{\mathrm{k}}=\left\langle\dot{\mathrm{H}}^{*}\right\rangle_{\mathrm{k}}+\epsilon_{\mathrm{k}}
$$

The values of $\epsilon_{\mathrm{k}}$ are normally distributed around zero; the standard deviation of this distribution, $\sigma_{\epsilon}$, can be estimated from the measured number of counts, i.e. from $\left\langle\dot{\mathrm{H}} \mathrm{MEAS}_{\mathrm{S}}^{*}\right\rangle_{\mathrm{k}}$.

It was shown that the Equations 3 and 9 taken together provide an estimate for the natural ambient dose rate, $\left\langle\dot{\mathrm{H}}_{\mathrm{NAT}}^{*}\right\rangle_{k}$, i.e.

$$
\left\langle\dot{\mathrm{H}}_{\mathrm{CALC}}^{*}\right\rangle_{\mathrm{k}} \equiv\left\langle\dot{\mathrm{H}}_{\mathrm{DRY}}^{*}\right\rangle_{\mathrm{k}}+\left\langle\dot{\mathrm{H}}_{\mathrm{WET}}^{*}\right\rangle_{\mathrm{k}}=\left\langle\dot{\mathrm{H}}_{\mathrm{NAT}}^{*}\right\rangle_{\mathrm{k}}+\delta_{\mathrm{k}}
$$

where $\delta_{k}$ is a variable representing the (unknown) difference between the calculated value and the true natural ambient dose rate. We assume here that the average value of all $\delta_{\mathrm{k}}$ values is zero and that the frequency distribution of any large population of $\delta_{k}$ is normal. The $\delta_{k}$ value of any randomly picked calculation can then be considered as a stochastic parameter whose probability is normally distributed around zero. The standard deviation of this distribution, $\sigma_{\delta}$, can be estimated from the uncertainty in the parameters used for the computation of $\left\langle\dot{\mathrm{H}}_{\mathrm{CALC}}^{*}\right\rangle_{\mathrm{k}}$. As was shown in Figure 3, the uncertainty in the ambient dose rate due to the washout of ${ }^{222} \mathrm{Rn}$ progeny is not normally distributed. To simplify the computation of $\sigma_{\delta}$, one may take the calculated bestestimate value of the ambient dose rate due to the wash- out of ${ }^{222} \mathrm{Rn}$ progeny as a conservative estimate of the $1 \sigma$ error in this component.

Now consider the measured and calculated data belonging to one arbitrary time interval, $\mathrm{k}$, which we subtract, one from the other. We then arrive at:

$$
\begin{aligned}
\left\langle\dot{\mathrm{H}}_{\mathrm{MEAS}}^{*}\right\rangle_{k} & -\left\langle\dot{\mathrm{H}}_{\mathrm{CALC}}^{*}\right\rangle_{\mathrm{k}} \equiv\left\langle\dot{\mathrm{H}}_{\mathrm{RES}}^{*}\right\rangle_{\mathrm{k}} \\
& =\left\langle\dot{\mathrm{H}}_{\mathrm{EVENT}}^{*}\right\rangle_{k}+\rho_{\mathrm{k}}
\end{aligned}
$$

where $\left\langle\dot{\mathrm{H}}_{\mathrm{RES}}^{*}\right\rangle_{k}$ is the residual ambient dose rate. Since there is no correlation between $\epsilon_{k}$ and $\delta_{k}, \rho_{k}$ is a zeromean stochastic variable, too, having a standard deviation, $\sigma_{\rho}$, equal to the 'quadratic sum' of $\sigma_{\epsilon}$ and $\sigma_{\delta}$. The question whether we are dealing with an event or not can now be solved on the basis of elementary statistics. We perform a two-tailed test on whether to accept or reject the null hypothesis that $\left\langle\dot{\mathrm{H}}_{\mathrm{EVENT}}^{*}\right\rangle_{\mathrm{k}}$ is zero, using a confidence level of $99.7 \%(\alpha=0.0016)$. We then have to reject the null hypothesis in the case:

$$
\left|\left\langle\dot{\mathrm{H}}_{\mathrm{RES}}^{*}\right\rangle_{\mathrm{k}}\right|>3.16 \sigma_{\mathrm{p}} \Leftrightarrow \frac{\left\langle\dot{\mathrm{H}}_{\mathrm{RES}}^{*}\right\rangle_{\mathrm{k}}^{2}}{\sigma_{\rho}^{2}}>10
$$

This criterion for anomalies may be applied to any singular data point. It is, however, not allowed to consider a time-series of data points and to perform, for instance, a $\chi^{2}$-test, because subsequent values of $\delta_{k}$, and therefore of $\rho_{k}$, are correlated (in contrast to $\epsilon_{k}, \delta_{k}$ drifts slowly around zero). If this were not the case, an even stricter criterion for anomalies could be established.

To validate the results obtained so far and to illustrate the usefulness of the compensation method presented above, various independent data sets were compared with calculated data. Figure 6 illustrates the results for NRM location Vlaardingen (433) in January 1992. The $\mathrm{C}_{0}$ value for this site equals $73.0 \mathrm{nSv} \cdot \mathrm{h}^{-1}$, with an uncertainty $(1 \sigma)$ of $0.7 \mathrm{nSv} \cdot \mathrm{h}^{-1}$ to include minor variations in the background not accounted for elsewhere. The timevarying input data are shown in Figure 6(a). Figure 6(b) compares measured and calculated best estimates, showing good agreement. Figure 6(c) compares the measured
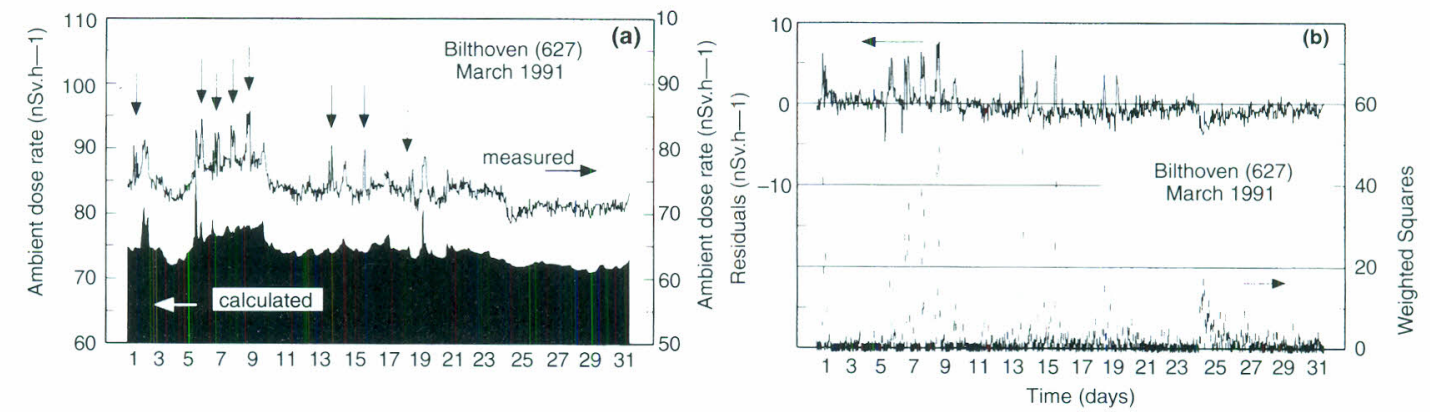

Figure 7. Comparison of measured and calculated ambient dose rates: (a) measured data (black line) and calculated best estimates (note the shifted vertical axes), and (b), residuals (black line) and 'weighted-squares' (scatter) (Equation 14). Human-induced spikes of about $5 \mathrm{nSv} \cdot \mathrm{h}^{-1}$ (arrows), only manifested during office hours, are due to the use of a strong $\gamma$ source in the vicinity of the measuring site. The dip around 25 March is caused by a solar event similar to the one presented in Figure 8, but on a much smaller scale. 
data with the estimated $95 \%$ uncertainty range of the natural ambient dose rate (not including counting statistics) and shows the measured data to be confined to this range. In Figure 6(d) the residuals are shown, as well as the 'weighted-squares' as given on the righthand side of Equation 14. The latter residuals were $<10$, in any case, making it unlikely that any particular event took place in that period.

Examples of data sets where events are evident are given in Figures 7 (a human practice) and 8 (a rare natural occurrence), using similar presentation schemes. On both occasions measured ambient dose rates deviate only by some $5 \mathrm{nSv} \cdot \mathrm{h}^{-1}$ from the (calculated) natural ambient dose rate but all events are decisively distinguished, showing that the method presented above can indeed be used for sensitive identification of deviating data.

\section{DISCUSSION AND CONCLUSIONS}

An analysis of six years data collected by the Dutch National Radioactivity Monitoring network revealed that temporal variations in the ambient dose rate can be modelled on the basis of four parameters, one fairly constant but location-dependent background value and three time-variable (local) parameters. The timevariable parameters, atmospheric pressure, precipitation rate and airborne radioactivity of short-lived ${ }^{222} \mathrm{Rn}$ progeny (expressed in EEDC) are readily available in the Netherlands, the EEDC since the NRM came into operation. The uncertainty in the calculated results depends on the specific environmental circumstances, but can be estimated fairly precisely.

Based on these results, a compensation method for the natural radiation background was developed that can be used to identify unusual events. The power of this technique was illustrated by two cases, showing that recordings deviating by some $5 \mathrm{nSv} \cdot \mathrm{h}^{-1}$ from the expected value are easily detected. However, these deviations were not recognised as unusual at the time of recording, because they fell in the common range of natural dose rate variations of about $100 \mathrm{nSv} \cdot \mathrm{h}^{-1}$. The actual detection limit for anomalies depends on current environmental conditions, but may be as low as (plus or minus) $2.5 \%$ of the typical background value (dry periods, low airborne radioactivity). When using this compensation technique, more definite conclusions can be drawn on questions as to whether or not radiation levels are (slightly) elevated, either for a temporary or prolonged period. Such questions may arise in both regular and emergency situations.

Deviating data can be the result of human interference, malfunction of equipment or rare natural phenomena (for instance, as observed in the summer of 1991). And although human expertise may still be required to judge anomalous situations it is obvious that applying a compensation method for natural ambient dose rate supports those who are in charge of the management of nuclear surveillance networks in various ways: first, by enhancing the performance of their primary task, i.e. quick and sensitive detection of elevated data; and secondly, by maintaining the required level of availability and quality assurance of the network. From the results obtained so far guidelines to reinforce operational procedures for the quality control of NRM data and equipment are in development. Moreover, results are incorporated in a new monitoring strategy for the surveillance of nuclear installations.

\section{ACKNOWLEDGEMENTS}

The authors are grateful to the Royal Netherlands Meteorological Institute (KNMI) for supplying them with detailed climatological data. They also thank Professor Dr A. van der Woude and Professor Dr R. J. de Meijer (Groningen University/KVI) for their stimulating comments and discussion and their colleagues at the RIVM for their loyal assistance.
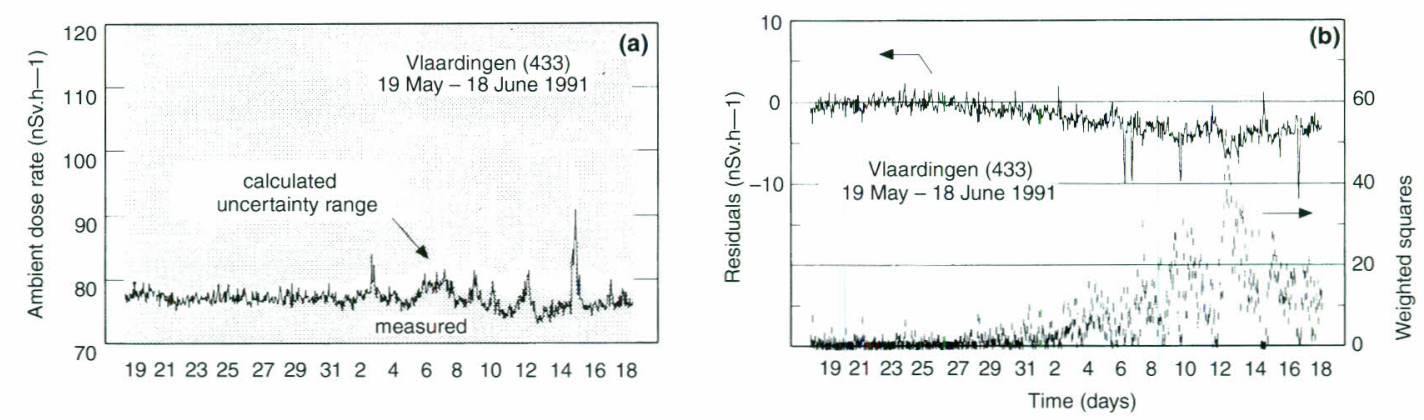

Figure 8. Comparison of measured and calculated ambient dose rates: (a) measured data (black line) and calculated uncertainty range (white area), and (b) residuals (black line) and 'weighted-squares' (scatter) (Equation 14). By the end of May measured data started to decrease due to a deflection of the earth magnetic field, hindering galactic cosmic rays entering the atmosphere. This decrease in the (cosmogenic) ambient dose rate at ground level, noticed at all the NRM locations, lasted for a number of months (Figure 5(a)). 


\section{REFERENCES}

1. UNSCEAR. Sources, Effects and Risks of Ionizing Radiation. UNSCEAR report 1993 (New York: United Nations) (1993).

2. ICRP. 1990 Recommendations of the International Commission on Radiological Protection. ICRP Publication 60, Ann. ICRP 21(1-3) (Oxford: Pergamon Press) (1991).

3. VROM. Radiation Protection and Risk Management (The Hague: Ministry of Housing, Physical Planning and the Environment) VROM publication 91377/a/10-91, SDU (1991).

4. Put, L. W. and Meijer, R. J. de Variation of Time-averaged Outdoor Radon Concentrations over a Distance of about 50 kilometres. Radiat. Prot. Dosim. 24(1/4), 97-99 (1988).

5. Dongen, R. van and Stoute, J. R. D. Outdoor Natural Background Radiation in the Netherlands. Sci. Total Environ. 45. 381-388 (1985).

6. Takeuchi, N. and Katase, A. Rainout-Washout Model for Variation of Environmental Gamma-Ray Intensity by Precipitation. J. Nucl. Sci. Technol. 19(5), 393-409 (1982).

7. Minato, S. Estimate of Radon-222 Concentrations in Rainclouds from Radioactivity Observed at Ground Level. J. Radioanal Chem. 78(1), 199-207 (1983).

8. Porstendörfer, J., Butterweck, G. and Reineking, A. Diurnal Variation of the Concentrations of Radon and its Short-lived Daughters in the Atmosphere near the Ground. Atmos. Environ. 25A(3/4), 709-713 (1991).

9. Nakashima, Y. and Fujisaka, S. On the Annual Variation of Photons Originating from Secondary Cosmic Ray Components at Sea Level at Nagoya, Japan. Radiat. Prot. Dosim. 45(1/4), 387-390 (1992).

10. Smetsers, R. C. G. M. and Lunenburg, A. P. P. A. van Evaluation of the Dutch Radioactivity Monitoring Network for Nuclear Emergencies over the Period 1990-1993. Radiat. Prot. Dosim. 55(3), 165-172 (1994).

11. Smetsers, R. C. G. M. and Blaauboer, R. O. Time-Resolved Monitoring of Outdoor Radiation Levels in the Netherlands Radiat. Prot. Dosim. 55(3), 173-181 (1994).

12. Smetsers, R. C. G. M. An Automated Gross- $\alpha / \beta$ Activity Monitor Applied to Time-resolved Quantitative Measurements of ${ }^{222}$ Rn Progeny in Air. Health Phys. 68(4), 546-552 (1995) (ISBN 90-367-0621-1).

13. Blaauboer, R. O. and Smetsers, R. C. G. M. Variations in Outdoor Radiation Levels in The Netherlands. Thesis. University of Groningen (1996) (ISBN 90-367-0621-1)

14. Bitt Technology. Radiation Monitor RMI0 - Gammasonde RSO2 (Technisches Manual) (Bitt Technology, Spillern) (1988).

15. International Commission on Radiation Units and Measurements. Measurement of Dose Equivalents from External Photon and Electron Radiations. ICRU Report 47 (Bethesda, USA: ICRU Publications) (1992).

16. Blaauboer, R. O. SOIL_RAD, a Computer Program to Calculate Air Kerma, Ambient Dose Rate and Effective Dose Rate due to Photons emitted by Radionuclides Distributed in Soil or on the Soil-Air Surface. (Bilthoven: National Institute of Public Health and the Environment) RIVM Report no 610064001 (1995).

17. Frenzel, E. Umgebungsüberwachung mit dem Aerosol-Monitor FHT 59 S. (Manual) (FAG Kugelfischer Georg Schäfer KGaA Erlangen) (1991).

18. Knutson, E. O. Modeling Indoor Concentrations of Radon's Decay Products. In: Radon and its Decay Products in Indoor Air. Eds W. W. Nazaroff and A. V. N. Nero (New York: Wiley) pp. 161-202 (1988).

19. KNMI. Klimatologische gegevens van Nederlandse stations; normalen en extreme waarden van 15 hoofdstations voor het tijdvak 1961-1990 (De Bilt: Royal Netherlands Meteorological Institute) KNMI Publication 150-27 (1992).

20. NCRP. Environmental Radiation Measurements. Recommendations of the National Council on Radiation Protection and Measurements, NCRP Report 50 (Washington, DC: NCRP) (1976).

21. Nielsen, S. P. Terrestrial and Cosmic Radiation in Denmark. In: Proc. Seminar on the Radiological Burden of Man from Natural Radioactivity in the Countries of the European Communities, Paris, 4-6 December 1979. CEC Report, pp. 101-110, V/2408/80 (1980).

22. O'Brien, K., Friedberg, W., Duke, F. E., Snyder, L., Darden, E. B. Jr and Sauer, H. H. The Exposure of Aircraft Crews to Radiations of Extraterrestrial Origin. Radiat. Prot. Dosim. 45(1/4), 145-162 (1992).

23. Jacobi, W. and André, K. The Vertical Distribution of ${ }^{222} R n,{ }^{220} R n$ and their Decay Products in the Atmosphere. J. Geophys. Res. 68, 3799-3814 (1963).

24. Annema, J. A., Booij, H., Hesse, J. M., Meulen, A. van der and Slooff, W. (eds) Integrated Criteria Document Fine Particu late Matter (Bilthoven: National Institute of Public Health and the Environment) RIVM Report no. 601014015 (1996).

25. Kocher, D. C. Dose-rate Conversion Factors for External Exposure to Photons and Electrons. Health Phys. 45(3), 665686 (1983).

26. Seinfeld, J. H. Atmospheric Chemistry and Physics of Air Pollution. (New York: Wiley) (1986).

27. Chamberlain, A. C. Radioactive Aerosols (Cambridge University Press) (1990).

28. Data on Cosmic Ray Indices and Magnetic Storms available from an on-line service (internet access) of the National Geophysical Data Center, Boulder, CO, USA. 
